\title{
Exploring impacts of marine heatwaves: paternal heat exposure diminishes fertilization success in the purple sea urchin (Strongylocentrotus purpuratus)
}

\author{
Terence S. Leach ${ }^{1}$ (D) Buyanzaya BuyanUrt ${ }^{1}$ - Gretchen E. Hofmann ${ }^{1}$ (1)
}

Received: 4 February 2021 / Accepted: 28 May 2021 / Published online: 19 June 2021

(C) The Author(s) 2021

\begin{abstract}
Marine heatwaves (MHWs) are projected to increase in intensity and frequency over the coming decades, and it is imperative to assess the adaptive capacity of marine organisms to these extreme temperature events. Given the nature of MHWs to last days to weeks in a region, these events may have overarching impacts on phenological events like reproduction and development. Here, the role of adult thermal history and transgenerational plasticity may be an important pathway by which MHWs are transduced to impact community structure. In this study, we sought to explore the effects of paternal thermal history in the purple urchin, Strongylocentrotus purpuratus, on a crucial aspect of reproduction, fertilization. Using ecologically relevant temperatures representative of both MHW events that occurred in 2014-2020 and non-MHW temperatures in our region of the California Large Marine Ecosystem, we conditioned male S. purpuratus for 28 days to either a high, MHW or a low, non-MHW temperature. Following the temperature acclimation of adults, sperm performance was tested for individual males by conducting fertilization success trials at varying temperatures and sperm concentrations. While sperm appeared robust to elevated temperature during fertilization, sperm produced by high-temperature-acclimated males had overall diminished performance as compared to those acclimated to non-MHW temperatures. These results suggest MHW events will have a negative impact on fertilization in situ for S. purpuratus populations. Furthermore, these results highlight the importance of considering both male and female environmental history in projections of reproduction under climate change scenarios.
\end{abstract}

\section{Introduction}

Understanding the adaptive capacity of species in response to climate change is a major research and conservation goal (Ofori et al. 2017; Thurman et al. 2020). In marine systems, for organisms not as reliant on migration and dispersal in response to unfavorable climatic conditions, adaptive capacity can be thought of as having two elements: micro-evolutionary processes (where genetic changes occur in response to selection in the environment) and phenotypic plasticity (where species change their physiology and morphology

Responsible Editor: P. Ramey-Balci.

Reviewed by: undisclosedexperts

Terence S. Leach

tleach@ucsb.edu

1 Department of Ecology, Evolution and Marine Biology, University of California Santa Barbara, Santa Barbara, CA 93106, USA without alteration to the underlying genome) (Hoffmann and Sgro 2011; Bay et al. 2018). Since phenotypic plasticity may act more rapidly, and on ecological time scales, this class of mechanisms might allow species to cope with environmental change in situ (Fox et al. 2019). In this study, we explore gamete plasticity and its effects on the fertilization process in the context of extreme heat stress that occurs during episodic marine heatwaves (MHWs), asking if paternal experience contributes to the generation of gametes more resistant to the thermal conditions of MHWs.

Marine heatwaves, represented by discrete periods of anomalously warm temperatures (compared to an area's historical baseline) lasting longer than 5 days (Hobday et al. 2016; Oliver et al. 2021), have increased in frequency in the last decade and estimates are that these anomalous heat events will occur with greater frequency in future global oceans (Frolicher et al. 2018; Oliver et al. 2018; Smale et al. 2019). Recent analysis by the IPCC and others predict that these events will become a decadal certainty in the high (RCP8.5) greenhouse gas emissions scenario, with MHW events by the end of century projected to occur every two 
days, last 126-152 days, and reach maximum temperatures $3.1{ }^{\circ} \mathrm{C}-3.8^{\circ} \mathrm{C}$ higher than the 99th percentile of temperatures from an area's historical baseline (IPCC 2019). Ecologically, MHW events threaten the biodiversity of marine coastal habitats through disruptions to ecosystem structure and function (Harris et al. 2018; Smale et al. 2019). On shorter timescales, intense thermal stress associated with these events can push organisms past their physiological limits, leading to massive mortality events (Wernberg et al. 2016; Harvell et al. 2019; Seuront et al. 2019). Even populations that can survive the initial temperature stress can manifest the effects of MHWs years later through altered reproductive and recruitment success (Pineda et al. 2018; Shanks et al. 2020), loss of habitat-forming species (Marba and Duarte 2010; Rogers-Bennett and Catton 2019), or the ecological consequences associated with poleward shifts of species into or out of parts of their biogeographic distributions (Sanford et al. 2019). These impacts on coastal marine ecosystems coupled with forecasts of more MHWs in the future together underscore the pressing need for more research into the biological consequences of MHWs, including whether specific populations have the adaptive capacity to withstand these short-term, extreme climatic events. Additionally, the formation of MHWs and their intensity is correlated to El Niño years, leading to regionally-specific temporal patterns in when these events are seen most frequently (i.e. from summer to early Fall along the west coast of North America) (Sen Gupta et al. 2020). Such seasonality must be considered when projecting what organismal functions and life history stages may be most impacted by future MHW events.

In coastal marine ecosystems along the Pacific coasts of North America, reproduction of benthic invertebrates varies but can be highly seasonal (Strathmann 1987). For example, many sea urchin species consistently undergo gametogenesis in the early fall and undergo spawning events the following winter (Cochran and Engelmann 1975). In addition, the response of marine taxa to environmental stressors, such as elevated temperature, varies with ontogeny, highlighting the need to consider life history in projections of a species' adaptive capacity (Przeslawski et al. 2015; Thurman et al. 2020). For species with complex life history strategies, as is the case for many marine invertebrates, early life history stages appear to be the most sensitive to the environmental stressors associated with ocean warming, ocean acidification, and hypoxia (Byrne 2011; Pandori and Sorte 2019). Extreme ocean warming experienced by these early stages has been documented to increase mortality, decrease growth, as well as promote stalled and abnormal development (Rahman et al. 2009; Randall and Szmant 2009; Byrne 2011; Martino et al. 2021). As many of these species are broadcast spawners that release their gametes directly into the water column to facilitate fertilization, their gametes also have the potential to be exposed to harsh conditions.

In contrast to the sensitivity of post-fertilization life stages, the general effect of increased temperature on gametes and the resulting fertilization is more contested. Fertilization can occur with unaltered success under moderate increases in temperature for many species (Byrne et al. 2010a; Enricuso et al. 2019; Pitts et al. 2020), with several studies observing positive effects of elevated temperature on echinoderm and mollusk fertilization (Ho et al. 2013; Foo et al. 2014; Eads et al. 2016b). Alternatively, a handful of studies document decreased fertility under high temperature (Parker et al. 2010; Albright and Mason 2013), with these conflicting results even observed within the same species challenged by similar temperatures (Byrne et al. 2009; Eads et al. 2016a; Chirgwin et al. 2020). These inconsistencies highlight the variability associated with measuring fertilization success as a result of differences in methods, parental crossing designs, distances between experimental temperatures from the study organism's thermal limits, and parental environmental histories (Byrne 2011). Given the importance of fertilization for both the success of individuals and populations, it is imperative to gain a better understanding of the mechanisms through which environmental stressors, like temperature, affect the fertilization process.

At the individual gamete-level, the morphology and physiology of both eggs and sperm influence fertilization success. For example, larger eggs provide a bigger target for increased fertilization (Levitan 2006) while sperm phenotype and motility can impact fertilization kinetics (Marshall 2015). While these factors can play a role in the success of fertilization under stressful environments, the phenotypes themselves may also be influenced by the environmental conditions experienced by the parents. Altered maternal provisioning to eggs is well documented in response to temperature, impacting egg size and content (Steer et al. 2004; Hamdoun and Epel 2007; Suckling et al. 2015). Alternatively, there is limited strong evidence across taxa that male thermal history can alter sperm quality and performance (Crean and Bonduriansky 2014; Boni et al. 2016; Immler 2018). In the tubeworm species, Galeolaria caespitosa, fertilization success was more influenced by paternal temperature environment than the temperature experienced during maternal conditioning, with significant decreases in fertilization $(-30 \%)$ seen in males exposed to $+6{ }^{\circ} \mathrm{C}$ for 14 days (Guillaume et al. 2016). While a few studies have tested other paternal environment factors on fertilization (Crean et al. 2013; Jensen et al. 2014), this is the only study to date testing the influence of temperature. Given the short timescales in which paternal effects can be seen, extreme climatic events like MHWs could disrupt the reproductive potential of populations through sire-related impacts on fertilization and development. 
To explore the impact of temperatures observed in MHW events on fertilization, we chose to study the ecologically and economically relevant purple sea urchin, Strongylocentrotus purpuratus (Pearse 2006). With a broad biogeographic distribution across the northeastern Pacific coast of North America, S. purpuratus populations are exposed to dynamic oceanic conditions associated with the temperature and $\mathrm{pH}$ mosaic observed within the California Current Large Marine Ecosystem (CCLME) (Chan et al. 2017). Ecologically, purple urchins are vital members of the kelp forest communities across the CCLME (Ebert 2010; Yorke et al. 2019). As grazers of kelp recruits, urchin density influences the shift of their habitat from a rich, kelp forest to a kelpdepleted "barren" and vice versa (Dayton et al. 1992). This role in shaping kelp forest communities has made monitoring changes in S. purpuratus populations a key element of studies assessing the health of kelp forests following MHW events (Reed et al. 2016; Rogers-Bennett and Catton 2019; Okamoto et al. 2020).

In general, the effect of temperature on urchin fertilization has been studied extensively (Rupp 1973; Sewell and Young 1999; Byrne et al. 2010a; Ericson et al. 2012; Foo et al. 2014; Mak and Chan 2018). While S. purpuratus served as the model for early work on general fertilization there are only a few studies exploring these dynamics in climate change scenarios. In these earlier studies, S. purpuratus fertilization success was independently sensitive to extremely high-temperature $\left(+10^{\circ} \mathrm{C}\right)$ and low $\mathrm{pH}$ conditions (Farmanfarmaian and Giese 1963; Kapsenberg et al. 2017). Given the environmental reality of future exposure to MHW conditions, in this study, we sought not only to explore the effects of elevated temperature on fertilization directly but also how the process was influenced by paternal heat exposure. Here, we acclimated groups of male adult urchins for 28 days at 2 temperature conditions-a non-MHW treatment $\left(14{ }^{\circ} \mathrm{C}\right)$ and a MHW treatment $\left(20^{\circ} \mathrm{C}\right)$. Treatment temperatures were chosen based upon temperature data collected from 2014-2020 within the Santa Barbara Channel (using the SBC LTER database: https://sbclter.msi.ucsb.edu/data/catal og/), where multiple MHW events were observed (see also Fig. 4 within Discussion section). Here, we report on the effects of MHW temperatures on aspects of fertilization biology and early life history events in S. purpuratus: (1) sperm performance via fertilization success trials, and (2) successful development of early stage embryos.

\section{Materials and methods}

\section{Animal collection}

Urchins were hand-collected on SCUBA in December 2019 from two separate temperate reef study sites in the Santa
Barbara Channel; these locations are also Santa Barbara Coastal Long-Term Ecological Research (LTER; https:// sbclter.msi.ucsb.edu/) sites: Mohawk Reef $\left(34.394^{\circ} \mathrm{N}\right.$, $\left.119.730^{\circ} \mathrm{W}\right)$ and Arroyo Quemado Reef $\left(34.468^{\circ} \mathrm{N}\right.$, $120.119^{\circ} \mathrm{W}$ ). Urchins in these locations, which are $~ 37 \mathrm{~km}$ apart, generally experience similar water temperature conditions and there is no evidence to suggest a difference in the timing of gravidity or reproduction between locations. Collections were conducted within a week of one another using California Scientific Collection permit SC-1223 (to G. Hofmann). Urchins from Mohawk Reef and Arroyo Quemado Reef were collected at depths of $8 \mathrm{ft}$. and $10 \mathrm{ft}$., respectively. Adult urchins were transported to the Marine Science Institute's seawater research facility and placed in flow-through seawater aquaria held at $13{ }^{\circ} \mathrm{C}$. Urchins from each location were kept separate and their location identity was tracked for the entirety of the study.

\section{Determination of urchin sex}

In the days following collection, urchins were sexed by a physical induction of spawning via one minute of shaking outside of water. From this process, 74 urchins (representing $\sim 67 \%$ of the total urchins attempted to be spawned) were successfully identified as either male ( $n=31$ urchins) or female ( $n=43$ urchins) and separated into appropriately labeled tanks. All urchins were given a recovery period at ambient temperatures while being fed kelp (Macrocystis pyrifera) ad libitum for 2-3 weeks following sexing. Any individual urchin that exhibited signs of significant injury, disease, or death during this period was promptly removed and not included in the experiment. Over the time spanning both recovery and the subsequent experimental acclimation, only 10 out of the original 111 urchins exposed to this spawning induction method were removed for signs of death or disease, indicating that this procedure for urchin sex identification did not significantly influence experimental results.

\section{Acclimation of adult sea urchins}

After the recovery period, male urchins were acclimated to either a high $\left(20^{\circ} \mathrm{C}\right)$ or low $\left(14{ }^{\circ} \mathrm{C}\right)$ temperature treatment for 28 days (Fig. 1). The 28-day acclimation period was used to both reflect a timeframe that is within the duration of past MHW events as well as overlap with the production of new sperm cells within the regularly fed male sea urchins (personal communication). This would increase the likelihood that the sperm used in this study included those produced under experimental conditions mimicking either ambient or ecologically relevant heat stress conditions. Male urchins were randomly selected and placed in one of the three acclimation tanks in either the high temperature $(\mathrm{H})$ or low-temperature treatment $(\mathrm{L})$. Test diameters for each urchin were 


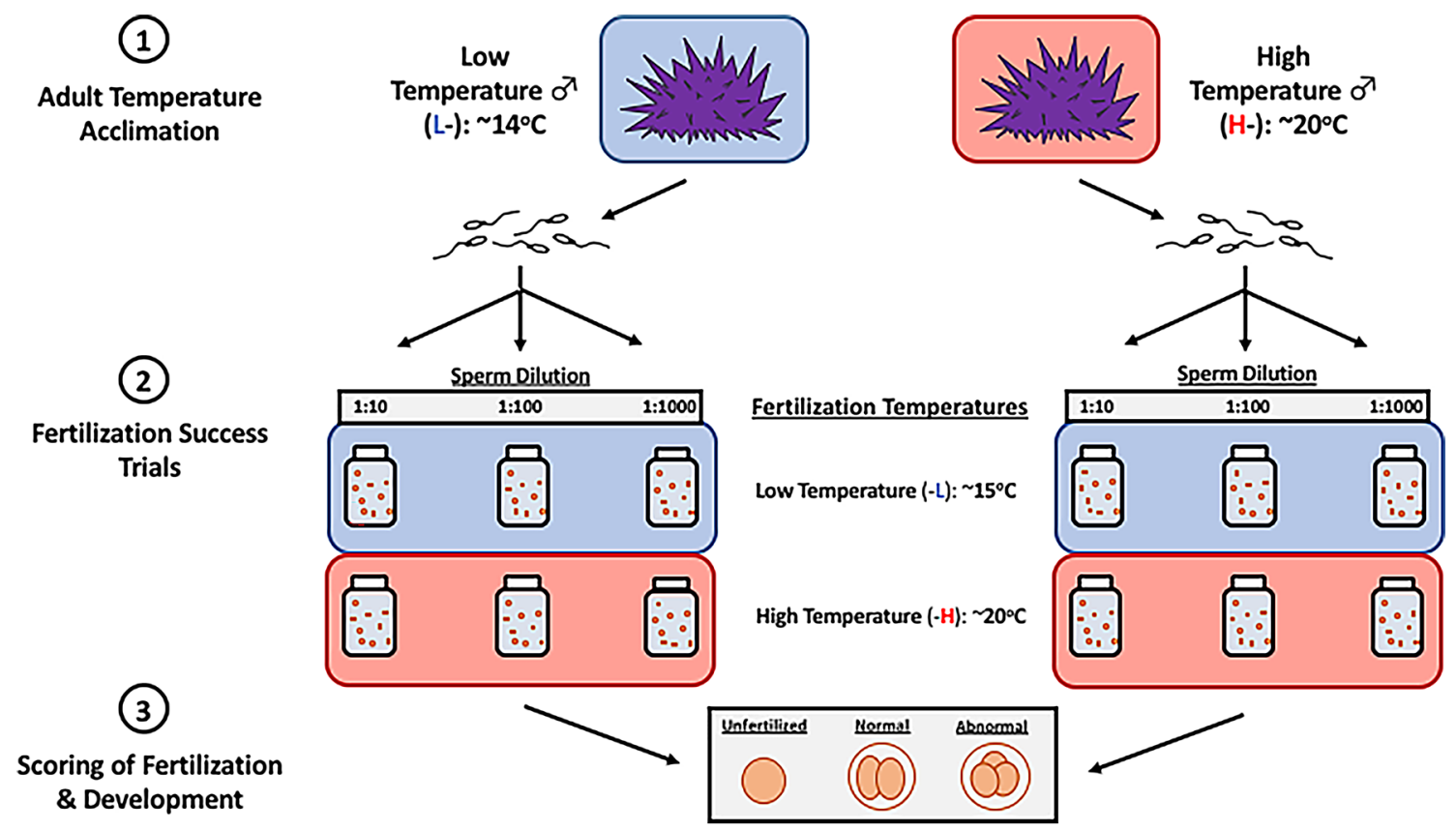

Fig. 1 Diagram of the experimental design, highlighting three main aspects of the process. (1) Adult male urchins were acclimated for 28 days at either a low $\left(\mathrm{L}-; 14{ }^{\circ} \mathrm{C}\right)$ or high $\left(\mathrm{H}-; 20^{\circ} \mathrm{C}\right)$ temperature treatment. (2) Urchins were then spawned to conduct a fertilization success assay for individual males from each treatment ( $n=9$ male urchins/treatment). Fertilization assays, performed at both a low (-L;

measured to ensure that no significant size difference existed between tanks or treatments. Acclimation tanks consisted of a 10-gallon tank equipped with an aquarium pump (AquaSupreme) and supplied with UV-sterilized, filtered seawater at a rate of $12 \mathrm{~L} / \mathrm{hr}$ through irrigation button drippers (DIG Corporation). Tanks from each treatment were halfway submerged in a large water bath where temperatures could be controlled. Seawater temperature was controlled using a Delta Star heat pump with a Nema $4 \times$ digital temperature controller (AquaLogic). Temperatures in each tank were monitored through point measurements with a wire thermocouple (Thermolyne PM 20,700 / Series 1218) and for the entirety of the acclimation, every $5 \mathrm{~min}$, by Hobo temperature loggers (Onset Computer Corporation). Once per week, each acclimation tank received one kelp blade per urchin present. Each weekly feeding interval lasted three days before any uneaten kelp material was removed. Female urchins were kept in multiple 10-gallon flow-through tanks maintained at ambient temperatures, approximately $13{ }^{\circ} \mathrm{C}$ and fed kelp ad libitum for the entirety of the male acclimation.

Due to the limited resources and time available for this study, adult acclimations and the following spawning were conducted in three blocks staggered by $96 \mathrm{~h}$ from one another. To facilitate these staggered adult acclimations, $\left.14^{\circ} \mathrm{C}\right)$ and high $\left(-\mathrm{H} ; 20^{\circ} \mathrm{C}\right)$ temperature, included serial dilution of each male's sperm to three different concentrations $(1: 10,1: 100$, $1: 1000$ ) and then a $30 \mathrm{~s}$ exposure to pooled eggs (portrayed here by orange circles within each vial) from multiple female urchins. (3) After a 2-h incubation at $14{ }^{\circ} \mathrm{C}$, eggs were scored for successful fertilization and subsequent development

each male acclimation tank was separated into three subdivisions representing each of the three blocks. For clarity, the first block of adult acclimations involved the random selection of 12 male urchins from the recovery tanks that were then placed into one subdivided section of 6 different tanks ( $n=2$ urchins per tank section), 3 replicate high-temperature acclimation tanks and 3 replicate low-temperature tanks. After $96 \mathrm{~h}$, the second block was initiated by selecting 12 more male urchins and placing them into a separate, subdivided section for each of the same 6 acclimation tanks previously mentioned. This process was repeated one last time $96 \mathrm{~h}$ after that for the third block of this experiment. Temperatures, $p \mathrm{CO}_{2}$ levels, and urchin behavior were closely monitored throughout to ensure that there were no significant disturbances to the urchins already present in the acclimation tanks when urchins were added or removed. This method was implemented to allow increased replication while ensuring that each block's male urchins endured exactly 28 days of acclimation before spawning without a significant amount of time between spawnings.

\section{Urchin spawning and experimental design}

During each block, male and female urchins were randomly selected to be spawned. Males from different replicate 
acclimation tanks were represented within each block. This time, urchin spawning was induced through a combination of intercoelomic injections of $0.55 \mathrm{M} \mathrm{KCl}$ and physical perturbation. Eggs were collected by inverting females over beakers filled with $\sim 15^{\circ} \mathrm{C}$ filtered seawater (FSW) and sperm was collected dry and kept on ice (Strathmann 1987). Gamete quantity and quality were observed under a light microscope. Gamete compatibility was assessed by conducting test fertilizations using every combination of males and females. During these test fertilizations, $15 \mathrm{uL}$ of concentrated eggs was added to $3 \mathrm{~mL}$ of FSW then oversaturated with sperm. Male urchins demonstrating healthy sperm (e.g. good motility and $>95 \%$ of eggs fertilized) were used to further assay fertilization success. Sperm was used within $6 \mathrm{~h}$ of collection.

Each block utilized a modified split-clutch crossing design for measuring fertilization success: involving the fertilization of pooled eggs ( $n=6$ females) by three males from each high and low treatments, resulting in 6 unique crosses. This crossing design with pooled eggs was utilized to minimize the effects of male-female interactions on fertilization and subsequent development. Across the three blocks, 9 males from each treatment and 3 pools of females were used to proxy this question over a total of 18 crosses.

\section{Protocol for fertilization success trials}

The consequences of paternal heat exposure were assessed by performing fertilization trials under two different fertilization temperatures across three sperm concentrations (Fig. 1). Trials were conducted following protocols outlined in Kapsenberg et al. (2017) and Crean et al. (2013). First, samples of each male's sperm were concentrated via centrifugation and excess fluid was removed, leading to a more standardized measure of sperm concentration across all individuals. Concentrated sperm from each male $(n=3$ males per treatment per block) were diluted 1:200 with FSW to create sperm stock solutions. Actual sperm concentrations were calculated post trial by preserving a subsample of each sperm stock in $2 \%$ formaldehyde-seawater and counting sperm cells using a hemocytometer (Hausser Scientific) (Sewell et al. 2014). From these stocks, serial dilutions were performed in triplicate $25-\mathrm{mL}$ glass vials to create $20-\mathrm{mL}$ solutions of three varying sperm concentrations $(1: 10$, $1: 100$, or $1: 1,000)$ for both fertilization temperature treatments. Depending on the treatment, sperm was diluted at this point using either $\mathrm{H}$ or L treated FSW. Temperatures within vials were maintained throughout the assay using a temperature-controlled aluminum block (for $\mathrm{H}$ treatment: $20{ }^{\circ} \mathrm{C}$ ) or a cold room (for $\mathrm{L}$ treatment: $15^{\circ} \mathrm{C}$ ) and measured via a thermocouple (Table 1). Target sperm concentrations were based off those used in past assays of $S$. purpuratus fertilization success (Kapsenberg et al. 2017), but targeting
Table 1 Temperatures measured during adult acclimations and fertilization success trials. All values displayed as mean \pm standard deviation

\begin{tabular}{llll}
\hline Acclimation & Duration & Treatment & Temperature $\left({ }^{\circ} \mathrm{C}\right)$ \\
\hline Adult & \multirow{2}{*}{ 28 days } & High Temp (H-) & $19.6 \pm 0.23$ \\
& & Low Temp (L-) & $13.5 \pm 0.42$ \\
Fertilization & \multirow{2}{*}{5 min } & High Temp (-H) & $19.8 \pm 0.65$ \\
& & Low Temp (-L) & $14.9 \pm 0.94$ \\
\hline
\end{tabular}

specific concentrations that led to $<100 \%$ fertilization under ambient conditions. Previous research suggests the use of lower sperm concentrations to more accurately assess the effect of environmental stressors on the fertilization process (Marshall 2006; Jensen et al. 2014; Guillaume et al. 2016). This justification applied specifically to the lower two sperm concentrations, but a third, higher sperm concentration (1:1000) was also included during the trials to both: (1) ensure that under the given conditions, sperm from each of our males would be able to fertilize all the eggs, and (2) provide potential information about the effect of MHW temperatures on the susceptibility of eggs to polyspermy. Vials of diluted sperm were homogenously resuspended by inversion before the addition of eggs.

For the trials, 1,000 eggs (suspended in $2 \mathrm{~mL} \mathrm{FSW}$ ) were added to each scintillation vial, bringing the total volume in each vial to $22 \mathrm{~mL}(\sim 45 \mathrm{eggs} / \mathrm{mL})$. For every trial, eggs were added to vials within $5 \mathrm{~min}$ of sperm activation for each male. Egg-sperm contact time was limited to $30 \mathrm{~s}$ after egg addition, with further fertilization events inhibited by adding $1 \mathrm{~mL}$ of $0.55 \mathrm{M} \mathrm{KCl}$ to each vial (Farley and Levitan 2001). A control vial, containing no sperm before egg addition, was run in conjunction with each trial's experimental vials to ensure that there was no sperm contamination or spontaneous fertilization envelope (FE) elevation during the trial that could skew results. Control vials containing even a single fertilized egg would invalidate that trial, leading it to be thrown out before any analysis was conducted. Once fertilization was inhibited, vials of fertilized eggs were kept at the treatment temperature ( $\mathrm{H}$ or $\mathrm{L})$ for around $5 \mathrm{~min}$ before they were moved to a $14{ }^{\circ} \mathrm{C}$ cold room and allowed to develop for at least $2 \mathrm{~h}$ before scoring for fertilization success (Table 2). Fertilization success was assayed for $>75$ eggs per vial. Successful development was scored by the presence of a smooth, elevated FE and equal, holoblastic cleavage. The number of unfertilized eggs and abnormal embryos (tight fertilization membranes or delayed/abnormal cleavage) were also scored (Sewell et al. 2014; Kapsenberg et al. 2017). These classifications were later used to assess two sides of the fertilization process: (1) fertilization events, or how well sperm was able to find and fuse with egg under the $30 \mathrm{~s}$ time limit, and (2) development, or how the subsequent cleavage proceeded 
Table 2 Scoring protocol for fertilization success assay

\begin{tabular}{lll}
\hline $\begin{array}{l}\text { Fertilization } \\
\text { Success }\end{array}$ & Description & Image \\
\hline Unfertilized & $\begin{array}{l}\text { No fertilization mem- } \\
\text { brane }\end{array}$ \\
Normal Embryo & $\begin{array}{l}\text { Normal fertilization } \\
\text { membrane; symmetri- } \\
\text { cal cleavage }\end{array}$ \\
$\begin{array}{l}\text { Tight fertilization mem- } \\
\text { Embrane or asymmetrical } \\
\text { cleavage }\end{array}$
\end{tabular}

after fertilization. The proportion of successful fertilization events was calculated by the following equation:
To determine if the sperm concentrations referenced in the model were themselves influenced by paternal temperature acclimation, the relationship between paternal temperature group and sperm concentration was examined using a Welch two-sample $t$ test. Additionally, the relationship between fertilization success and the sperm concentrations corresponding to dilutions $(1: 10,1: 100,1: 1000)$ for each individual male were analyzed by linear regression and found no significant correlation $\left(R^{2}<0.1\right)$, so concentrations were binned into three categories (HIGH for 1:10, MID for 1:100, LOW for 1:1000) for use in the previously described model.

Analysis of how paternal temperature affected the proportion of fertilized eggs that developed normally was also analyzed with a generalized linear mixed-effects model. This dataset, again modeled as a binomial response fitted with the logit link function, excluded data points corresponding to eggs fertilized under the LOW sperm concentration as

Proportion Fertilization Events $=($ Total eggs - Unfertilized eggs $) /$ Total eggs

The proportion of normally and abnormally developed embryos were then calculated from the eggs that were fertilized: all replicates had $<10$ eggs that had even been fertilized to start with. As such, sperm concentration, now containing only two categories (MID and HIGH), was modeled as a fixed effect in addition to paternal temperature treatment and

Proportion Normal Development $=$ Normally developing embryos $/$ Fertilized eggs

Proportion Abnormal Development $=$ Abnormally developing embryos $/$ Fertilized eggs

Out of the 36 fertilization trials conducted for this experiment, only one revealed the presence of fertilization in the control. This trial (testing an $\mathrm{H}$ male's fertilization success at the $\mathrm{L}$ fertilization environment) was thrown out and not considered during data analysis.

\section{Statistical analysis}

The influence of paternal temperature on the proportion of fertilization events observed was analyzed as a binomial response with a generalized linear mixed-effects model. The binary data (fertilized vs unfertilized) were fitted using a logit link function. The model included paternal temperature treatment, fertilization temperature treatment, and sperm concentration as fixed effects in addition to both experimental round and male identity as random effects. Nonsignificant random terms, such as site location and some of the interactions between fixed factors, were removed from the analysis following standard model reduction procedures outlined in Quinn and Keough 2002. A Wald chi-square test was employed to further determine the significance of each factor on the number of fertilization events observed. fertilization temperature treatment. Male identity and round were included as random effects once again. Again, nonsignificant random terms were removed following standard model reduction procedures and a Wald chi-square test was utilized to determine whether each factor had a significant effect on normal development (Quinn and Keough 2002). All statistical analysis was performed in $\mathrm{R}$ (version 3.6.3) with models created using the lmer4 package (Bates et al. 2015).

\section{Results}

\section{Fertilization events}

In general, male thermal history significantly impacted the number of successful fertilization events observed in vitro at all sperm concentrations (Table $3 ; p=0.035$ ). In addition, both sperm concentration alone, and the interaction between sperm concentration and the temperature at which fertilization occurred, had significant effects in the model (Table 3). Within each sperm concentration, a lower proportion of 
Table 3 Statistical output (Wald chi-square test) from generalized linear mixed-effects model used to analyze the effect of paternal temperature and fertilization temperature on the proportion of fertilization events seen across three sperm concentrations

\begin{tabular}{lrrc}
\hline & \multicolumn{1}{c}{$\chi^{2}$} & $d f$ & \multicolumn{1}{l}{$p$} \\
\hline Sperm Concentration Group & 2747.66 & 2 & $<0.001^{*}$ \\
Paternal Temperature & 4.46 & 1 & $0.035^{*}$ \\
Fertilization Temperature & 2.78 & 1 & 0.096 \\
Sperm Concentration Group * & 17.65 & 2 & $0.002^{*}$ \\
$\quad$ Fertilization Temperature & & & \\
\hline
\end{tabular}

eggs were fertilized by sperm from high-temperature males (HIGH: $97.2 \pm 0.7 \%$, MID: $44.3 \pm 2.4 \%$, LOW: $6.2 \pm 0.6 \%$, presented as mean \pm standard error) as compared to sperm from low-temperature males (HIGH: $98.0 \pm 0.7 \%$, MID: $53.7 \pm 3.1 \%$, LOW: $9.2 \pm 0.8 \%$ ) (Fig. 2). The effect of paternal temperature was most pronounced under the middle (MID) sperm concentration, where high-temperature males produced sperm that resulted in $\sim 9 \%$ less fertilization than that of low-temperature males. The other sperm concentrations exhibited a similar pattern but to a lesser degree, with high-temperature males having $3 \%$ and $~ 1 \%$ less fertilization under the most dilute (LOW) and concentrated (HIGH) sperm conditions, respectively.

Not surprisingly, sperm concentration was a highly influential parameter in the experiment, displaying a positive relationship with the proportion of fertilized eggs observed (Table 3; $p<0.001$ ). Measured sperm concentrations, calculated from a sample taken from each male's original sperm stock solution, averaged $1.46 \times 10^{6} \pm 7.32 \times 10^{4}$ sperm. $\mathrm{mL}^{-1}$. There was no observed difference between the sperm concentrations produced by differentially acclimated males ( $t$ $(16)=0.043, p=0.9663$ ), with sperm concentrations from high-temperature males averaging $1.48 \times 10^{6} \pm 1.11 \times 10^{5}$ sperm. $\mathrm{mL}^{-1}$ compared to $1.44 \times 10^{6} \pm 9.81 \times 10^{4}$ sperm. $\mathrm{mL}^{-1}$ in low-temperature males. Based on these calculations and estimations from conducted serial dilutions, we assume that the concentrations were roughly $10^{5}, 10^{4}$, and $10^{3}$ sperm. $\mathrm{mL}^{-1}$ for the HIGH, MID-, and LOW sperm concentration groups, respectively. The proportion of fertilized eggs increased positively with these estimated sperm concentrations (Fig. 2), with a majority of eggs remaining unfertilized in the most dilute sperm conditions (LOW: $7.7 \pm 0.54 \%$ ) to nearly all eggs exhibiting fertilization under the most concentrated sperm conditions (HIGH: $97.6 \pm 0.49 \%$ ). The MID-sperm concentration exhibited an almost even split between the fertilized and unfertilized eggs observed $(48.9 \pm 2.1 \%)$. These concentrations also exhibited an interactive effect with fertilization temperature (Table 3; $p=0.002$ ). Note that there was no significant effect of fertilization temperature alone on the proportion of fertilized events observed (Table 3; $p=0.096$ ).

\section{Development of embryos}

There was not a detectable effect of paternal thermal history on the proportion of fertilized eggs that cleaved normally (Table $4 ; p=0.35$ ). Alternatively, there were significant effects of sperm concentration and the interaction between
Fig. 2 Effects of sperm concentration (low, mid, high), paternal temperature experience (L-, $\left.14{ }^{\circ} \mathrm{C} ; \mathrm{H}-, 20^{\circ} \mathrm{C}\right)$ and fertilization temperature treatment $(-\mathrm{L}$, $\left.15^{\circ} \mathrm{C} ;-\mathrm{H}, 20^{\circ} \mathrm{C}\right)$ on the percentage of fertilization events in the urchin S. purpuratus. Error bars represent mean \pm standard error

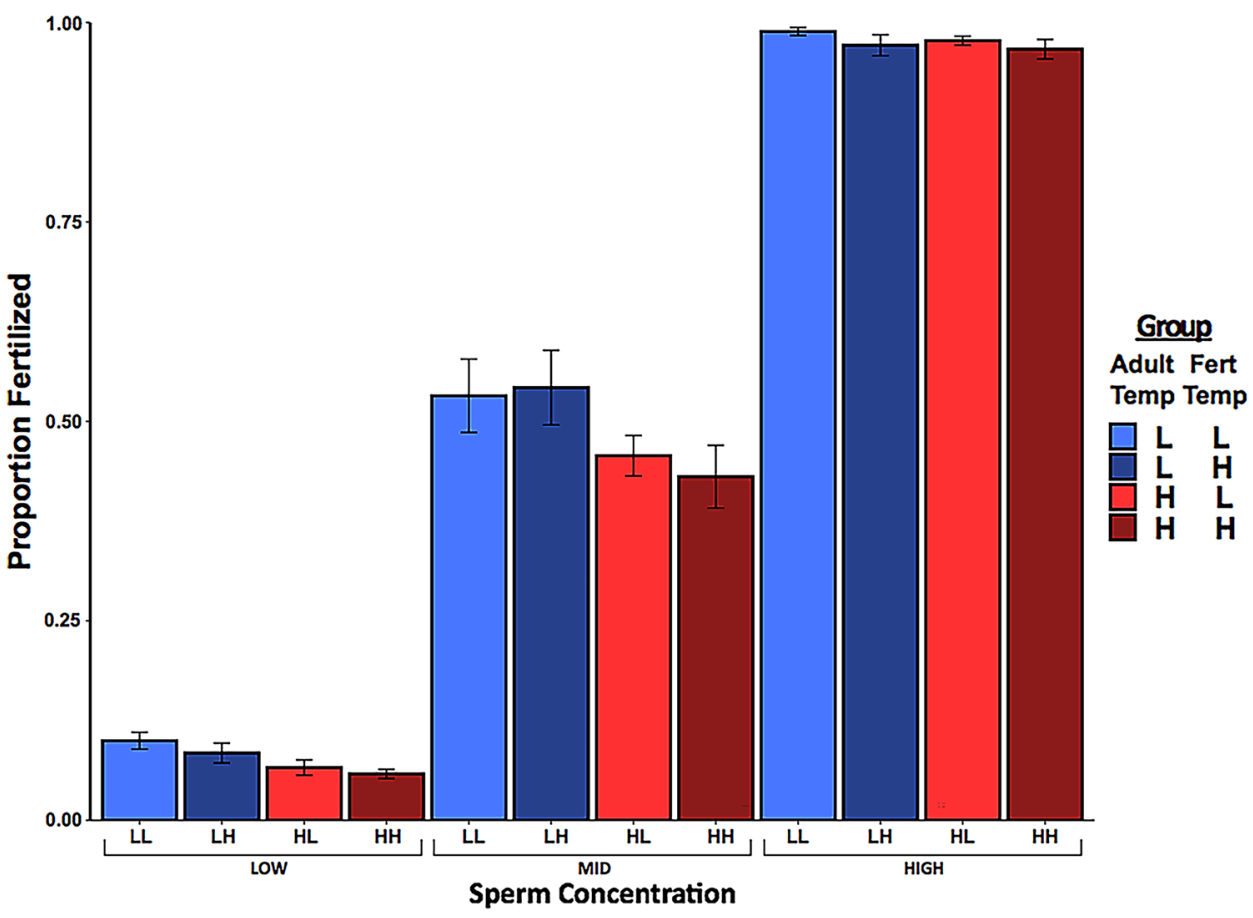


Table 4 Statistical output (Wald chi-square test) from generalized linear mixed-effects model used to analyze the effect of paternal temperature and fertilization temperature on the proportion of normally developed embryos seen across two sperm concentrations

\begin{tabular}{lrrr}
\hline Source & \multicolumn{1}{l}{$\chi^{2}$} & $d f$ & \multicolumn{1}{l}{$p$} \\
\hline Sperm Concentration Group & 1027.99 & 1 & $*<0.001$ \\
Paternal Temperature & 0.86 & 1 & 0.353 \\
Fertilization Temperature & 1.79 & 1 & 0.181 \\
Sperm Concentration Group $*$ & 6.68 & 1 & $* 0.010$ \\
$\quad$ Paternal Temperature & & & \\
\hline
\end{tabular}

sperm concentration and paternal thermal history (Table 4). As the trials associated with the LOW sperm concentration all yielded $<10$ fertilized eggs, they were not included in this analysis due to low sample sizes. In comparing the normal development of fertilized eggs between the MID and HIGH sperm groups, we observed a large significant effect of sperm concentration (Table $4 ; p<0.001$ ). The proportion of normally developed fertilized eggs was diminished with higher sperm concentration, with only $32.5 \pm 1.7 \%$ of fertilized eggs developing normally under high concentrations as opposed to $75.4 \pm 1.9 \%$ for the middle concentrations (Fig. 3). While there was no significant effect of either paternal or fertilization temperature on the proportion of normal development (Table $4 ; p=0.18$ ), under the HIGH sperm concentration, embryos from high-temperature males that experienced high temperatures during fertilization exhibited more normal development $(37.5 \pm 2.9 \%)$ than any other combination of paternal and fertilization temperatures (HL:
$31.3 \pm 2.7 \%$, LH: $28.7 \pm 4.4 \%$, LL: $31.4 \pm 3.5 \%$ ). This pattern was not observed under the MID-sperm concentration, driving the significant interactive effect of concentration and paternal temperature seen in the model (Table $4 ; p=0.01$ ).

\section{Discussion}

In this study, we examined the fertilization success of the purple sea urchin, Strongylocentrotus purpuratus, under the elevated temperatures associated with marine heatwave (MHW) scenarios. Our experimental goal was to determine how MHW-like temperatures experienced during spermatogenesis and fertilization would influence the fertilization process. To meet this goal, adult male sea urchins were exposed to two temperatures, $14{ }^{\circ} \mathrm{C}$ or $20^{\circ} \mathrm{C}$, for 28 days before their sperm was assessed via fertilization success trials under the same temperature treatments. In examining the role of paternal thermal history on fertilization dynamics under these temperatures, we discovered two central findings: (1) the temperature at which fertilization occurred had no significant effect on fertilization itself, and (2) paternal exposure to a MHW-like temperature had a negative impact on fertilization success as compared to the non-MHW treatment. Underlying the second finding is the observation that these patterns in fertilization success were driven mainly by a reduced ability of the sperm to reach the egg and fertilize it as opposed to abnormal development seen post-fertilization. Below we discuss each aspect of our study and relate our results to
Fig. 3 Effects of sperm concentration (mid and high), paternal temperature experience, and fertilization temperature treatment on developmental success in the urchin S. purpuratus. Bars represent the proportion of normally developed embryos from eggs that were fertilized. Error bars represent mean \pm standard error

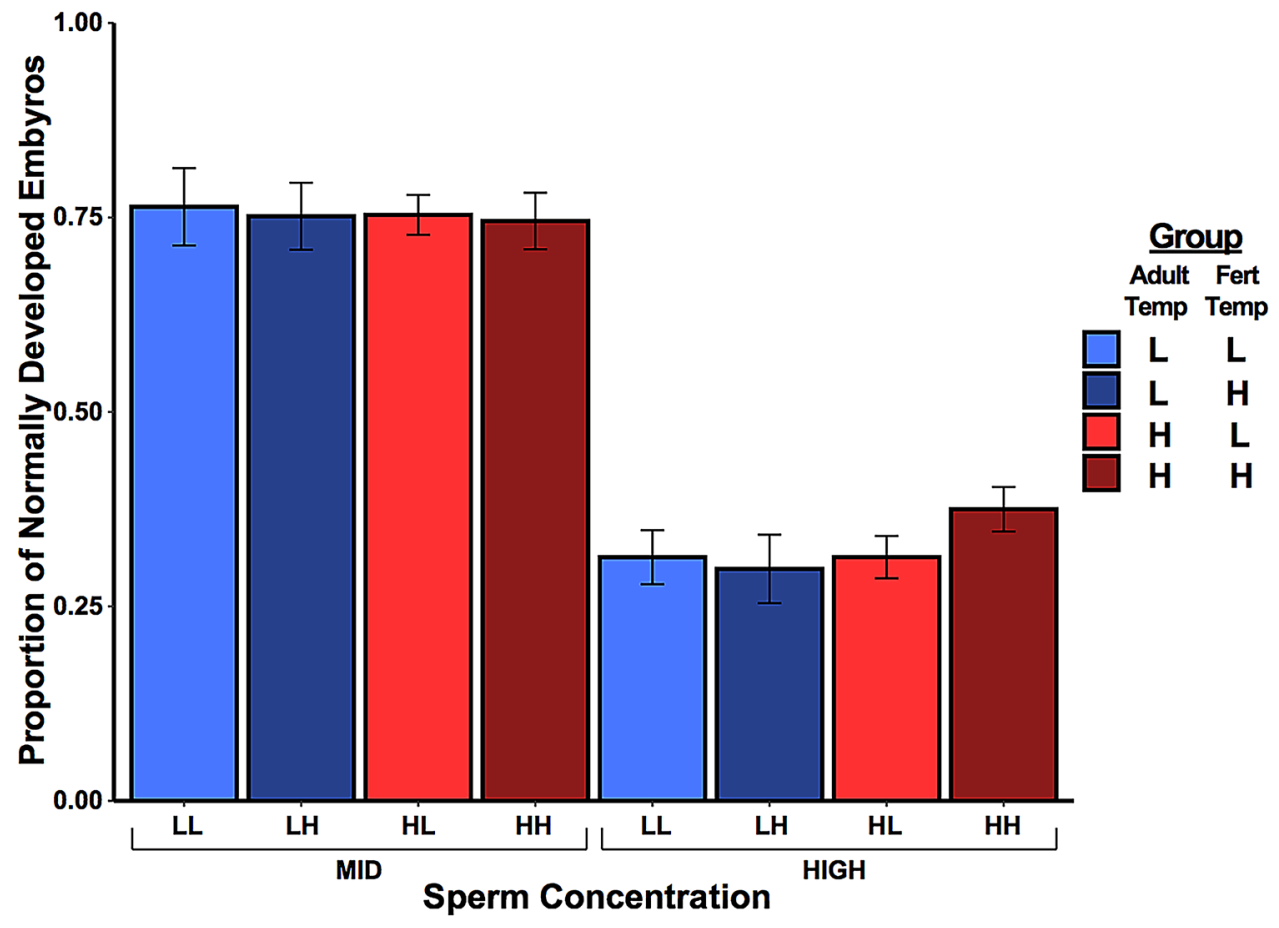


the phenology of the sea urchin life cycle relative to the timing of MHWs in our area.

\section{Fertilization robust to high temperature}

In our study, fertilization in S. purpuratus, regardless of paternal thermal history, was not significantly altered by high temperature. Successful fertilization under a high, MHW-like temperature $\left(20^{\circ} \mathrm{C}\right)$ was observed at similar proportions to fertilization occurring under a low, non-MHW temperature $\left(15^{\circ} \mathrm{C}\right)$. Although we did not directly measure any sperm traits in this study, a scoring design was utilized that allowed for more insight into what elements of the fertilization process could be most influenced by temperature. The presence of a fertilization membrane alone was used to calculate the proportion of fertilization events observed, which could serve as a proxy for general fertilization kinetics involved in the sperm reaching the egg and fertilizing it in a defined time frame. We then measured how many of those fertilized eggs demonstrated normal cleavage after $2 \mathrm{~h}$ at $14{ }^{\circ} \mathrm{C}$, allowing for the assessment of abnormality caused by polyspermy, male-female incompatibility, or sperm DNA damage. Here, neither the proportion of fertilization events or normally cleaving embryos were significantly altered by fertilization temperature, but the effect was just nonsignificant $(p=0.095)$ for the number of fertilization events observed. Together, these results align with the prevailing view that fertilization in sea urchins displays a great deal of plasticity and is generally robust under ocean warming scenarios (Byrne 2011).

In terms of species comparisons, studies focused on how temperature affects sea urchin fertilization biology report some contrasting and species-dependent results. Most tropical and temperate sea urchins demonstrate successful fertilization over a wide range of temperatures, even under temperature challenges much higher than what the urchin populations experience in situ (Rupp 1973; Byrne et al. 2010b; Delorme and Sewell 2014; Foo et al. 2014). Several echinoid species across coastal Australia exhibit high fertilization success $(>80 \%)$ when challenged with temperatures 2-6 ${ }^{\circ} \mathrm{C}$ higher than that experienced locally (Byrne et al. 2010b; Foo et al. 2014). Alternatively, the fertilization of a few temperate and polar species exhibits a lower thermal tolerance threshold (Farmanfarmaian and Giese 1963; Byrne et al. 2009; Ericson et al. 2012; Gianguzza et al. 2014). Such vulnerabilities have renewed relevance when considering the anomalously high temperatures associated with current MHW events. For example, while the Mediterranean sea urchin species, Arbicula lixula, exhibited successful fertilization at temperatures above that predicted under near-future warming scenarios, the complete disruption of fertilization $(<1 \%)$ at temperatures $7{ }^{\circ} \mathrm{C}$ above ambient conditions leave A. lixula vulnerable to MHW events experienced in the area over the past decade (Olita et al. 2007; Gianguzza et al. 2014). Circumstances such as this are only becoming more common with increased MHW prevalence across global oceans (Oliver et al. 2018), potentially leaving species with narrow fertilization thermal tolerance windows, like the Antarctic sea urchin, Sterechinus neumayeri (Ericson et al. 2012; Ho et al. 2013), at risk sooner than projected under ocean warming scenarios.

This species-dependent thermal tolerance of fertilization is observed across other marine invertebrate taxa as well, including corals (Negri et al. 2007; Albright and Mason 2013) and mollusks (Parker et al. 2010; Armstrong et al. 2019; Enricuso et al. 2019). There is also evidence that a great deal of intra-species variability in fertilization success exists, with contrasting results observed in the mussel, Mytilus edilus (Eads et al. 2016a, 2016b), the sea urchin, Heliocidaris erthyogramma (Byrne et al. 2009, 2010a, 2010b), and the polychaete, Galeolaria caespitosa (Kupriyanova and Havenhand 2005; Chirgwin et al. 2020). This variation highlights the need to consider other factors, both biological (e.g. environmental history of study populations) and methodological (e.g. experimental design), that could influence fertilization dynamics under altered temperatures.

Methodological differences in fertilization success assays are common across studies, an issue prompting the creation of a more standardized approach for environmental monitoring (Lera et al. 2006). The type of crossing design used, for example, can heavily influence results, with the use of pooled gametes reducing the effects of male-female incompatibilities (Byrne et al. 2009; Eads et al. 2016b) and benefitting from the positive contributions of polyandry (Evans and Marshall 2005), while individual male-female pairings instead illuminate the extent of intra-individual variability within fertilization (Foo et al. 2014; Eads et al. 2016a). Our study employed the less-frequently used split-clutch design where sperm from individual males were used to fertilize eggs from the same pool of females (Crean et al. 2013). While some variability between males (within each paternal temperature treatment) did exist, this method appeared to conform to results seen in population-level approaches with no general effect of temperature on fertilization. Alternatively, fertilization success was significantly altered by the sperm concentration used, providing more evidence that these concentrations are an important factor to consider in the design of fertilization success assays (Marshall 2015). Here, the proportion of fertilization events increased positively with sperm concentration, most likely a result of more gamete collisions at higher ratios of sperm to egg (Kupriyanova and Havenhand 2002). The highest sperm concentration, estimated to be $10^{5}$ sperm. $\mathrm{mL}^{-1}$, led to significant amounts of abnormality $(\sim 70 \%)$. This perceived polyspermy could have been induced by the combination 
of sperm concentration, contact time between gametes, and vessel size utilized in this study (Byrne 2011).

Studies aimed at uncovering the mechanistic basis of how temperature influences fertilization success could provide more standardized results in addition to accounting for individual variability. Research on fertilization under temperature stress attributes varied tolerance to differential maternal investment of heat shock factors to eggs (Yamada and Mihashi 1998) in addition to altered sperm kinetics and energy metabolism (Mita et al. 1984; Johnson and Yund 2004). For sperm specifically, elevated temperatures can increase the cell's metabolic rate, visualized through diminished sperm longevity and increased respiration (Kupriyanova and Havenhand 2005; Rahman et al. 2009; Binet and Doyle 2013). As such, the inclusion of varied contact times between egg and sperm in addition to quantifications of sperm longevity, motility and respiration could provide useful insight for future studies quantifying fertilization under MHW scenarios.

Overall, the varying thermal tolerance of fertilization within and across marine taxa may support the idea that there is not one general effect of the environment on sperm cells but instead certain conditions that favor specific sperm phenotypes, affecting the fertilization success landscape (Marshall 2015). For example, the optimal head size of sperm cells of the tubeworm, Galeolaria gemineoa, was found to differ depending on the concentration and age of the sperm, with longer heads favored under both low concentrations and amongst aged sperm, as opposed to fertilization under high sperm concentrations where smaller heads (with longer tails) possessed increased success (Johnson et al. 2013). If this selection for specific sperm morphology holds true for other environmental conditions, the increased variation in sperm phenotypes associated with pooled sperm samples could heavily influence fertilization success results, especially when compared to studies using sperm from single males. Therefore, it is prudent for future studies of fertilization success to consider measures of sperm phenotypes in addition to what factors could influence the production of these specific phenotypes, such as paternal environmental history.

\section{Paternal environment alters fertilization success}

Based upon previous research on temperature effects in marine invertebrates (O'Connor et al. 2007; Zippay and Helmuth 2012), we hypothesized that paternal heat exposure would have a negative impact on fertilization success. Our results support this hypothesis as we observed diminished proportions of successfully fertilized eggs in male urchins exposed to $20{ }^{\circ} \mathrm{C}$ as opposed to $14{ }^{\circ} \mathrm{C}$ for 28 days. Similar, if not pronounced, results were seen in the tubeworm, Galeolaria caespitosa following a 2-week exposure of male and female worms to varied temperatures (Guillaume et al. 2016). For G. caespitosa, fertilization success in warm acclimated $\left(21.5^{\circ} \mathrm{C}\right)$ males was significantly lower than that of cool acclimated males $\left(15.5{ }^{\circ} \mathrm{C}\right)$ across multiple sperm concentrations. To date, these are the only two studies that have explored the effect of paternal thermal acclimation on fertilization success in marine systems.

One pathway by which temperature could influence paternal function is via direct effects on gametogenesis. Generally, elevated temperatures can alter the gametogenesis process for both male and female organisms, but can be particularly detrimental to sperm production (Rogers-Bennett et al. 2010; Uthicke et al. 2014). Even when sperm are successfully produced under temperature stress, thermal history can be reflected in the sperm quality and performance (Boni et al. 2016; Johnstone et al. 2019). In this study, all male $S$. purpuratus were successfully spawned after a 28 -day acclimation to $20^{\circ} \mathrm{C}$, but the sperm produced during this period had diminished performance regarding fertilization. Paternal exposure to high temperature exhibited a significant negative effect on the number of fertilization events observed across different sperm concentrations (LOW: -3\%, MID: $-9 \%$, LOW: $-1 \%)$. These patterns could potentially reflect compromised fertilization kinetics resulting from paternal temperature stress via alterations of sperm morphology, motility, or processes associated with sperm chemotaxis or acrosomal function (Immler 2018). Mussels exposed to $28{ }^{\circ} \mathrm{C}$ for a similar period of time ( 30 days) exhibited both decreased sperm motility and increased abnormality (Boni et al. 2016). Here, sperm from both paternal temperature treatments demonstrated nearly $100 \%$ fertilization at the highest sperm concentration, providing little evidence to suggest high-temperature males produced sperm that was unable to contact or fertilize eggs when given the opportunity (Marshall 2006). Environmental stress can additionally affect sperm quality in the form of DNA damage within the sperm cells themselves, leading to developmental abnormalities in embryos and larvae (Lewis and Galloway 2009; Johnstone et al. 2019). For S. purpuratus used in this study, measures of post-fertilization development (cleavage) varied only with sperm concentration, not with fertilization or paternal temperature alone.

While the presence of environmentally induced maternal effects has been acknowledged for years (Mousseau and Fox 1998), the potential for non-genetic paternal effects is just beginning to gain traction (Crean and Bonduriansky 2014; Marshall 2015). Depending on the predictability of the environment, adaptive paternal effects could exist where males under stressful conditions can confer tolerance to offspring experiencing similar environments (Marshall 2015). Positive impacts on larval survival, metamorphosis, and growth have been observed in response to perceived sperm competition (Crean et al. 2013) and salinity (Jensen et al. 2014), but not 
pH (Lane et al. 2015). Jensen et al. (2014) found that fertilization success in the tubeworm, Hydroides diramphus, was at its highest when the salinity during fertilization matched that experienced by both parents. In this study, we found that the exposure of male $S$. purpuratus to elevated temperatures did not confer any positive effects onto the fertilization process even when fertilization temperatures matched that experienced by the sires. All eggs used in fertilization trials came from dams kept at ambient conditions so we were unable to determine if these fertilization success results changed when both parents experienced a similar stress.

Alternatively, the extent of adaptive paternal effects observed during fertilization may depend on the duration of the adult acclimation to stressful conditions (Stillman 2003; Seebacher et al. 2014). As such, longer (or shorter) exposure of male urchins to the temperatures used in this study could result in additional shifts in the overall fertilization success seen. Guillaume et al. (2016) observed more dramatic decreases in fertilization success when male tubeworms were kept at elevated temperatures for 14 days, half the time we acclimated urchins for in this study. In that same study, larval survival was also measured at 14 days and exhibited a similarly negative response to temperature, but when authors assessed survival again after 28 days, this result had been ameliorated. The research question in this study was fueled by the growing threat of MHWs, which can vary significantly in duration and intensity. As such, these questions would be aided by future experiments directed toward elucidating the extent that paternal (and maternal) effects change in response to temperature over different timescales.

\section{Summary \& Implications in a MHW-context}

The results of our study suggest MHWs will have a significant impact on marine invertebrate reproduction through alterations to the quality and performance of produced gametes. Other investigators have shown that MHW events can disrupt marine ecosystem structure and function through increased mortality events (Harvell et al. 2019; Seuront et al. 2019), diminished recruitment success (Okamoto et al. 2020; Shanks et al. 2020), and altered ecological interactions (Sanford et al. 2019). In our work, an empirical approach using MHW-like conditions $\left(20^{\circ} \mathrm{C}\right)$ in the lab revealed another potential negative outcome for marine invertebrate populations, altered reproductive output through diminished fertilization success. Paternal acclimation and fertilization treatments in this study were selected based on temperature data collected over the past 6 years at the study sites in which we collect S. purpuratus (Fig. 4). MHW events from 2013 to 2020 were defined using these temperature data and a baseline climatology created from temperatures recorded over the past $\sim 17$ years (Hobday et al. 2016). During this time, populations of urchins and other marine invertebrates in the Santa Barbara Channel (SBC) have been exposed to multiple MHW events of varying lengths and intensities, with temperatures seen exceeding the $20^{\circ} \mathrm{C}$ treatment used here.

Additionally, observations of MHWs in the SBC add more evidence of these events' seasonality (Sen Gupta et al. 2020). MHWs seen in 2014, 2015, and 2018 all occurred within late summer to Fall, times during which temperatures are at their highest of the year. The timing of these MHWs threatens the overlapping seasonality of $S$. purpuratus reproduction, where the bulk of gametogenesis

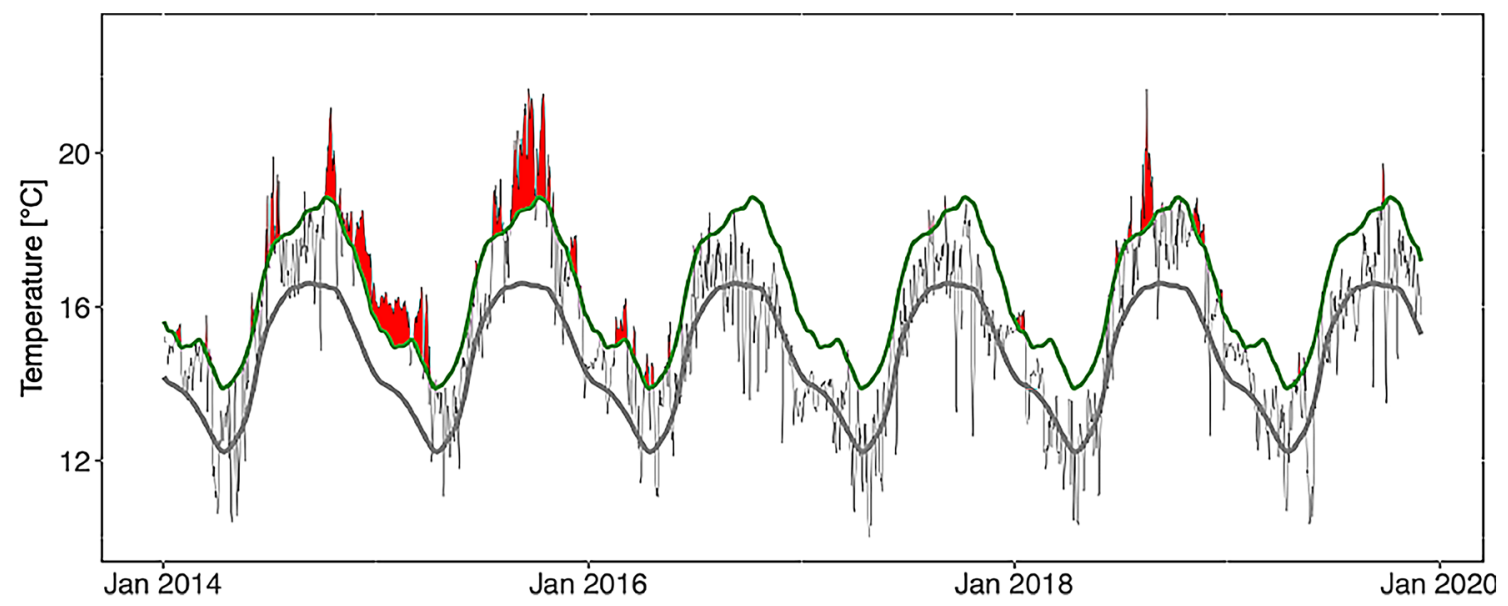

Fig. 4 Marine heatwave events in the Santa Barbara Channel (SBC) over a 6-year period. From January 2014 to January 2020, marine heatwave events were calculated at an SBC LTER site, Arroyo Quemado. Temperature data were collected at the benthos and on a LTER mooring using ONSET Tidbit loggers. MHW events were calculated using heatwaveR, where the long-term climatology seasonal cycle (gray line), seasonal variation threshold at the $90^{\text {th }}$ percentile (green line), and MHW events occurring for at least 5 days (red areas) were determined from average daily temperature data taken at this site from 2003 to 2012 
occurs from October to January (Strathmann 1987). This phenology places our results in an ecologically relevant context. MHW events can last anywhere from 5 days to multiple months and are only expected to become more frequent and longer in duration over the next decade (Frolicher et al. 2018; Oliver et al. 2018; Smale et al. 2019). Results from this study indicate that current and future MHW events lasting around one month can negatively impact the fertilization success of individual male urchins. While fertilization itself was unaltered by the MHW-like temperatures, pre-spawning exposure of males to elevated temperatures was harmful. If similar effects were seen in nature, the reproductive output of sea urchin populations could be significantly altered by lower numbers of larvae produced or increased selection on particular genotypes from males who are the most competitive under these environments (Campbell et al. 2016). While this study only acknowledges the effect of temperature stress on an early developmental bottleneck, fertilization, negative responses to MHW events within later developmental stages of sea urchins have also been observed (Martino et al. 2021). Additionally, one must also consider the potential of significant carryover effects not explored here, where the effects of this exposure of parents and/or gametes to MHW temperatures could appear much later in development (Byrne and Hernandez 2020). Past MHW events in the SBC already coincided with decreased $S$. purpuratus biomass and recruitment (Reed et al. 2016; Okamoto et al. 2020). Together these data point toward MHW events as a potentially significant factor in the persistence and structure of sea urchin populations across the CCLME.

Acknowledgements This research was supported by NSF award IOS-1656262 to G.E.H. This work was also supported by resources from Santa Barbara Coastal Long-Term Ecological Research program (NSF award OCE-1831937; Director: Dr. Robert Miller), an award for which GEH is a co-PI. T.S.L. was supported by a Ford Predoctoral Fellowship. The Gorman Scholars Program provided support for B.B. Specimens were collected in the Santa Barbara Channel under a California Scientific Collecting Permit to G.E.H. (SC-1223). Our appreciation goes out to Clint Nelson for collection of animals. We are also extremely grateful for the assistance provided by Logan Kozal, Jannine Chamorro, Xochitl Clare, Samuel Bogan, Amelia Ritger, Adriane McDonald, Cailan Sugano, Avery DeSantis, and Alix Martin during the experiment. We also would like to thank Dr. Kathy Foltz and Dr. Debora Iglesias-Rodriguez for the feedback provided during the writing of this manuscript.

Authors' contributions Conceptualization and design: TSL, GEH; methodology: TSL, BB; data analysis: TSL, BB; writing-original draft preparation: TSL, GEH; writing — review and editing: TSL, BB, GEH. All authors read and approved the final manuscript.

Data availability The datasets generated during and/or analyzed during the current study are available in a Gitbhub repository (https://github. com/tleach32/Spurp-MHW-Fert_2021).

\section{Declarations}

Conflict of interest The authors have no conflict of interest to declare.

Ethical approval All applicable international, national and/or institutional guidelines for sampling, care and experimental use of organisms for the study have been followed and all necessary approvals have been obtained.

Open Access This article is licensed under a Creative Commons Attribution 4.0 International License, which permits use, sharing, adaptation, distribution and reproduction in any medium or format, as long as you give appropriate credit to the original author(s) and the source, provide a link to the Creative Commons licence, and indicate if changes were made. The images or other third party material in this article are included in the article's Creative Commons licence, unless indicated otherwise in a credit line to the material. If material is not included in the article's Creative Commons licence and your intended use is not permitted by statutory regulation or exceeds the permitted use, you will need to obtain permission directly from the copyright holder. To view a copy of this licence, visit http://creativecommons.org/licenses/by/4.0/.

\section{References}

Albright R, Mason B (2013) Projected near-future levels of temperature and $\mathrm{pCO}(2)$ reduce coral fertilization success. PLoS ONE. https://doi.org/10.1371/journal.pone.0056468

Armstrong EJ, Dubousquet V, Mills SC, Stillman JH (2019) Elevated temperature, but not acidification, reduces fertilization success in the small giant clam. Tridacna Maxima Marine Biology 167:8. https://doi.org/10.1007/s00227-019-3615-0

Bates D, Machler M, Bolker BM, Walker SC (2015) Fitting linear mixed-effects models using lme4. J Stat Softw 67:1-48. https:// doi.org/10.18637/jss.v067.i01

Bay RA, Harrigan RJ, Le Underwood V, Gibbs HL, Smith TB, Ruegg K (2018) Genomic signals of selection predict climate-driven population declines in a migratory bird. Science. https://doi.org/ $10.1126 /$ science.aan 4380

Binet MT, Doyle CJ (2013) Effect of near-future seawater temperature rises on sea urchin sperm longevity. Mar Freshwater Res 64:1-9. https://doi.org/10.1071/Mf12121

Boni R, Gallo A, Montanino M, Macina A, Tosti E (2016) Dynamic changes in the sperm quality of Mytilus galloprovincialis under continuous thermal stress. Mol Reprod Dev 83:162-173. https:// doi.org/10.1002/mrd.22604

Byrne M (2011) Impact of ocean warming and ocean acidification on marine invertebrate life history stages Vulnerabilities and potential for persistence in a changing climate. In: Gordon J (ed) Oceanography and Marine Biology. CRC Press, Boca Raton

Byrne M, Hernandez JC (2020) Sea urchins in a high CO2 world: Impacts of climate warming and ocean acidification across life history stages. Dev Aquac Fish Sci 43:281-297. https://doi.org/ 10.1016/B978-0-12-819570-3.00016-0

Byrne M, Ho M, Selvakumaraswamy P, Nguyen HD, Dworjanyn SA, Davis AR (2009) Temperature, but not $\mathrm{pH}$, compromises sea urchin fertilization and early development under near-future climate change scenarios. P Roy Soc B-Biol Sci 276:1883-1888. https://doi.org/10.1098/rspb.2008.1935

Byrne M, Soars N, Selvakumaraswamy P, Dworjanyn SA, Davis AR (2010a) Sea urchin fertilization in a warm, acidified and high $\mathrm{pCO}(2)$ ocean across a range of sperm densities. Mar Environ 
Res 69:234-239. https://doi.org/10.1016/j.marenvres.2009.10. 014

Byrne M, Soars NA, Ho MA, Wong E, McElroy D, Selvakumaraswamy P, Dworjanyn SA, Davis AR (2010b) Fertilization in a suite of coastal marine invertebrates from SE Australia is robust to nearfuture ocean warming and acidification. Mar Biol 157:2061-2069. https://doi.org/10.1007/s00227-010-1474-9

Campbell AL, Levitan DR, Hosken DJ, Lewis C (2016) Ocean acidification changes the male fitness landscape. Sci Rep-Uk. https:// doi.org/10.1038/srep31250

Chan F, Barth JA, Blanchette CA, Byrne RH, Chavez F, Cheriton O, Feely RA, Friederich G, Gaylord B, Gouhier T, Hacker S, Hill T, Hofmann G, McManus MA, Menge BA, Nielsen KJ, Russell A, Sanford E, Sevadjian J, Washburn L (2017) Persistent spatial structuring of coastal ocean acidification in the California Current System. Sci Rep-Uk. https://doi.org/10.1038/s41598-017-02777-y

Chirgwin E, Marshall DJ, Monro K (2020) Physical and physiological impacts of ocean warming alter phenotypic selection on sperm morphology. Funct Ecol 34:646-657. https://doi.org/10.1111/ 1365-2435.13483

Cochran RC, Engelmann F (1975) Environmental regulation of annual reproductive season of Strongylocentrotus-Purpuratus (Stimpson). Biol Bull 148:393-401. https://doi.org/10.2307/1540516

Crean AJ, Bonduriansky R (2014) What is a paternal effect? Trends Ecol Evol 29:554-559. https://doi.org/10.1016/j.tree.2014.07.009

Crean AJ, Dwyer JM, Marshall DJ (2013) Adaptive paternal effects? Experimental evidence that the paternal environment affects offspring performance. Ecology 94:2575-2582. https://doi.org/10. 1890/13-0184.1

Dayton PK, Tegner MJ, Parnell PE, Edwards PB (1992) Temporal and Spatial Patterns of Disturbance and Recovery in a Kelp Forest Community. Ecol Monogr 62:421-445. https://doi.org/10.2307/ 2937118

Delorme NJ, Sewell MA (2014) Temperature and salinity: two climate change stressors affecting early development of the New Zealand sea urchin Evechinus chloroticus. Mar Biol 161:1999-2009. https://doi.org/10.1007/s00227-014-2480-0

Eads AR, Evans JP, Kennington WJ (2016a) Plasticity of fertilization rates under varying temperature in the broadcast spawning mussel, Mytilus galloprovincialis. Ecol Evol 6:6578-6585. https://doi.org/ 10.1002/ece3.2375

Eads AR, Kennington WJ, Evans JP (2016b) Interactive effects of ocean warming and acidification on sperm motility and fertilization in the mussel Mytilus galloprovincialis. Mar Ecol Prog Ser 562:101-111. https://doi.org/10.3354/meps11944

Ebert TA (2010) Demographic patterns of the purple sea urchin Strongylocentrotus purpuratus along a latitudinal gradient, 1985-1987. Mar Ecol Prog Ser 406:105-120. https://doi.org/10.3354/meps0 8547

Enricuso OB, Conaco C, Sayco SLG, Neo ML, Cabaitan PC (2019) Elevated seawater temperatures affect embryonic and larval development in the giant clam Tridacna gigas (Cardiidae: Tridacninae). J Mollus Stud 85:66-72. https://doi.org/10.1093/mollus/eyy051

Ericson JA, Ho MA, Miskelly A, King CK, Virtue P, Tilbrook B, Byrne M (2012) Combined effects of two ocean change stressors, warming and acidification, on fertilization and early development of the Antarctic echinoid Sterechinus neumayeri. Polar Biol 35:10271034. https://doi.org/10.1007/s00300-011-1150-7

Evans JP, Marshall DJ (2005) Male-by-female interactions influence fertilization success and mediate the benefits of polyandry in the sea urchin Heliocidaris erythrogramma. Evolution 59:106-112

Farley GS, Levitan DR (2001) The role of jelly coats in sperm-egg encounters, fertilization success, and selection on egg size in broadcast spawners. Am Nat 157:626-636. https://doi.org/10. $1086 / 320619$
Farmanfarmaian A, Giese AC (1963) Thermal tolerance and acclimation in the western purple sea urchin, Strongylocentrotus purpuratus. Physiol Biochem Zool. https://doi.org/10.1086/physzool. 36.3.30152309

Foo SA, Dworjanyn SA, Khatkar MS, Poore AGB, Byrne M (2014) Increased temperature, but not acidification, enhances fertilization and development in a tropical urchin: potential for adaptation to a tropicalized eastern Australia. Evol Appl 7:1226-1237. https:// doi.org/10.1111/eva.12218

Fox RJ, Donelson JM, Schunter C, Ravasi T, Gaitan-Espitia JD (2019) Beyond buying time: the role of plasticity in phenotypic adaptation to rapid environmental change. Philos T R Soc B. https://doi. org/10.1098/rstb.2018.0174

Frolicher TL, Fischer EM, Gruber N (2018) Marine heatwaves under global warming. Nature. https://doi.org/10.1038/ s41586-018-0383-9

Gianguzza P, Visconti G, Gianguzza F, Vizzini S, Sara G, Dupont S (2014) Temperature modulates the response of the thermophilous sea urchin Arbacia lixula early life stages to $\mathrm{CO} 2$-driven acidification. Mar Environ Res 93:70-77. https://doi.org/10.1016/j.maren vres.2013.07.008

Guillaume AS, Monro K, Marshall DJ (2016) Transgenerational plasticity and environmental stress: do paternal effects act as a conduit or a buffer? Funct Ecol 30:1175-1184. https://doi.org/10.1111/ 1365-2435.12604

Hamdoun A, Epel D (2007) Embryo stability and vulnerability in an always changing world. P Natl Acad Sci USA 104:1745-1750. https://doi.org/10.1073/pnas.0610108104

Harris RMB, Beaumont LJ, Vance TR, Tozer CR, Remenyi TA, Perkins-Kirkpatrick SE, Mitchell PJ, Nicotra AB, McGregor S, Andrew NR, Letnic M, Kearney MR, Wernberg T, Hutley LB, Chambers LE, Fletcher MS, Keatley MR, Woodward CA, Williamson G, Duke NC, Bowman DMJS (2018) Biological responses to the press and pulse of climate trends and extreme events (vol 8,pg 579, 2018). Nat Clim Change 8:840-840. https:// doi.org/10.1038/s41558-018-0237-3

Harvell CD, Montecino-Latorre D, Caldwell JM, Burt JM, Bosley K, Keller A, Heron SF, Salomon AK, Lee L, Pontier O, PattengillSemmens C, Gaydos JK (2019) Disease epidemic and a marine heat wave are associated with the continental-scale collapse of a pivotal predator (Pycnopodia helianthoides). Sci Adv. https://doi. org/10.1126/sciadv.aau7042

Ho MA, Price C, King CK, Virtue P, Byrne M (2013) Effects of ocean warming and acidification on fertilization in the Antarctic echinoid Sterechinus neumayeri across a range of sperm concentrations. Mar Environ Res 90:136-141. https://doi.org/10.1016/j. marenvres.2013.07.007

Hobday AJ, Alexander LV, Perkins SE, Smale DA, Straub SC, Oliver ECJ, Benthuysen JA, Burrows MT, Donat MG, Peng M, Holbrook NJ, Moore PJ, Scannell HA, Sen Gupta A, Wernberg T (2016) A hierarchical approach to defining marine heatwaves. Prog Oceanogr 141:227-238. https://doi.org/10.1016/j.pocean.2015.12.014

Hoffmann AA, Sgro CM (2011) Climate change and evolutionary adaptation. Nature 470:479-485. https://doi.org/10.1038/nature09670

Immler S (2018) The sperm factor: paternal impact beyond genes. Heredity 121:239-247. https://doi.org/10.1038/ s41437-018-0111-0

IPCC (2019) Summary for policymakers. In: Pörtner H-O, Roberts DC, Masson-Delmotte V, Zhai P, Tignor M, Poloczanska E, Mintenbeck K, Nicolai M, Okem A, Petzold J, Rama B, Weyer N (eds) IPCC Special Report on the ocean and cryosphere in a changing climate. IPCC, Geneva, Switzerland

Jensen N, Allen RM, Marshall DJ (2014) Adaptive maternal and paternal effects: gamete plasticity in response to parental stress. Funct Ecol 28:724-733. https://doi.org/10.1111/1365-2435.12195 
Johnson SL, Yund PO (2004) Remarkable longevity of dilute sperm in a free-spawning colonial ascidian. Biol Bull 206:144-151. https:// doi.org/10.2307/1543638

Johnson DW, Monro K, Marshall DJ (2013) The Maintenance of sperm variability: context-dependent selection on sperm morphology in a broadcast spawning invertebrate. Evolution 67:1383-1395. https:// doi.org/10.1111/evo.12022

Johnstone J, Nash S, Hernandez E, Rahman MS (2019) Effects of elevated temperature on gonadal functions, cellular apoptosis, and oxidative stress in Atlantic sea urchin Arbacia punculata. Mar Environ Res 149:40-49. https://doi.org/10.1016/j.marenvres.2019. 05.017

Kapsenberg L, Okamoto DK, Dutton JM, Hofmann GE (2017) Sensitivity of sea urchin fertilization to $\mathrm{pH}$ varies across a natural $\mathrm{pH}$ mosaic. Ecol Evol 7:1737-1750. https://doi.org/10.1002/ece3. 2776

Kupriyanova E, Havenhand JN (2002) Variation in sperm swimming behaviour and its effect on fertilization success in the serpulid polychaete Galeolaria caespitosa. Invertebr Reprod Dev 41:21-26. https://doi.org/10.1080/07924259.2002.9652731

Kupriyanova EK, Havenhand JN (2005) Effects of temperature on sperm swimming behaviour, respiration and fertilization success in the serpulid polychaete, Galeolaria caespitosa (Annelida : Serpulidae). Invertebr Reprod Dev 48:7-17. https://doi.org/10.1080/ 07924259.2005.9652166

Lane A, Campanati C, Dupont S, Thiyagarajan V (2015) Trans-generational responses to low $\mathrm{pH}$ depend on parental gender in a calcifying tubeworm. Sci Rep-Uk. https://doi.org/10.1038/srep10847

Lera S, Macchia S, Pellegrini D (2006) Standardizing the methodology of sperm cell test with Paracentrotus lividus. Environ Monit Assess 122:101-109. https://doi.org/10.1007/s10661-005-9167-4

Levitan DR (2006) The relationship between egg size and fertilization success in broadcast-spawning marine invertebrates. Integr Comp Biol 46:298-311. https://doi.org/10.1093/icb/icj025

Lewis C, Galloway T (2009) Reproductive Consequences of Paternal Genotoxin Exposure in Marine Invertebrates. Environ Sci Technol 43:928-933. https://doi.org/10.1021/es802215d

Mak KKY, Chan KYK (2018) Interactive effects of temperature and salinity on early life stages of the sea urchin Heliocidaris crassispina. Mar Biol. https://doi.org/10.1007/s00227-018-3312-4

Marba N, Duarte CM (2010) Mediterranean warming triggers seagrass (Posidonia oceanica) shoot mortality. Global Change Biol 16:2366-2375. https://doi.org/10.1111/j.1365-2486.2009.02130.x

Marshall DJ (2006) Reliably estimating the effect of toxicants on fertilization success in marine broadcast spawners. Mar Pollut Bull 52:734-738. https://doi.org/10.1016/j.marpolbul.2006.05.005

Marshall DJ (2015) Environmentally induced (co)variance in sperm and offspring phenotypes as a source of epigenetic effects. J Exp Biol 218:107-113. https://doi.org/10.1242/jeb.106427

Martino C, Byrne M, Roccheri MC, Chiarelli R (2021) Interactive effects of increased temperature and gadolinium pollution in Paracentrotus lividus sea urchin embryos: a climate change perspective. Aquat Toxicol. https://doi.org/10.1016/j.aquatox.2021. 105750

Mita M, Hino A, Yasumasu I (1984) Effect of temperature on interaction between eggs and spermatozoa of sea-urchin. Biol Bull 166:68-77. https://doi.org/10.2307/1541431

Mousseau TA, Fox CW (1998) The adaptive significance of maternal effects. Trends Ecol Evol 13:403-407. https://doi.org/10.1016/ S0169-5347(98)01472-4

Negri AP, Marshall PA, Heyward AJ (2007) Differing effects of thermal stress on coral fertilization and early embryogenesis in four Indo Pacific species. Coral Reefs 26:759-763. https://doi.org/10. 1007/s00338-007-0258-2
O'Connor MI, Bruno JF, Gaines SD, Halpern BS, Lester SE, Kinlan BP, Weiss JM (2007) Temperature control of larval dispersal and the implications for marine ecology, evolution, and conservation. P Natl Acad Sci USA 104:1266-1271. https://doi.org/10.1073/ pnas.0603422104

Ofori BY, Stow AJ, Baumgartner JB, Beaumont LJ (2017) Influence of adaptive capacity on the outcome of climate change vulnerability assessment. Sci Rep-Uk. https://doi.org/10.1038/ s41598-017-13245-y

Okamoto DK, Schroeter S, Reed DC (2020) Effects of ocean climate on spatiotemporal variation in sea urchin settlement and recruitment. Limnol Oceanogr 65:2076-2091. https://doi.org/10.1002/ lno. 11440

Olita A, Sorgente R, Natale S, Gabersek S, Ribotti A, Bonanno A, Patti B (2007) Effects of the 2003 European heatwave on the Central Mediterranean Sea: surface fluxes and the dynamical response. Ocean Sci 3:273-289. https://doi.org/10.5194/os-3-273-2007

Oliver ECJ, Donat MG, Burrows MT, Moore PJ, Smale DA, Alexander LV, Benthuysen JA, Feng M, Sen Gupta A, Hobday AJ, Holbrook NJ, Perkins-Kirkpatrick SE, Scannell HA, Straub SC, Wernberg T (2018) Longer and more frequent marine heatwaves over the past century. Nat Commun. https://doi.org/10.1038/ s41467-018-03732-9

Oliver ECJ, Benthuysen JA, Darmaraki S, Donat MG, Hobday AJ, Holbrook NJ, Schlegel RW, Gupta AS (2021) Marine Heatwaves. Ann Rev Mar Sci 13:313-342. https://doi.org/10.1146/annur ev-marine-032720-095144

Pandori LLM, Sorte CJB (2019) The weakest link: sensitivity to climate extremes across life stages of marine invertebrates. Oikos 128:621-629. https://doi.org/10.1111/oik.05886

Parker LM, Ross PM, O'Connor WA (2010) Comparing the effect of elevated $\mathrm{pCO}(2)$ and temperature on the fertilization and early development of two species of oysters. Mar Biol 157:2435-2452. https://doi.org/10.1007/s00227-010-1508-3

Pearse JS (2006) Perspective - Ecological role of purple sea urchins. Science 314:940-941. https://doi.org/10.1126/science.1131888

Pineda J, Reyns N, Lentz SJ (2018) Reduced barnacle larval abundance and settlement in response to large-scale oceanic disturbances: Temporal patterns, nearshore thermal stratification, and potential mechanisms. Limnol Oceanogr 63:2618-2629. https://doi.org/10. 1002/lno.10964

Pitts KA, Campbell JE, Figueiredo J, Fogarty ND (2020) Ocean acidification partially mitigates the negative effects of warming on the recruitment of the coral, Orbicella faveolata. Coral Reefs 39:281292. https://doi.org/10.1007/s00338-019-01888-4

Przeslawski R, Byrne M, Mellin C (2015) A review and meta-analysis of the effects of multiple abiotic stressors on marine embryos and larvae. Global Change Biol 21:2122-2140. https://doi.org/ $10.1111 / \mathrm{gcb} .12833$

Quinn GP, Keough MJ (2002) Experimental design and data analysis for biologists. Cambridge University Press

Rahman MS, Tsuchiya M, Uehara T (2009) Effects of temperature on gamete longevity and fertilization success in two sea urchin species, Echinometra mathaei and Tripneustes gratilla. Zool Sci 26:1-8. https://doi.org/10.2108/zsj.26.1

Randall CJ, Szmant AM (2009) Elevated temperature affects development, survivorship, and settlement of the elkhorn coral, Acropora palmata (Lamarck 1816). Biol Bull 217:269-282. https://doi.org/ 10.1086/BBLv217n3p269

Reed D, Washburn L, Rassweiler A, Miller R, Bell T, Harrer S (2016) Extreme warming challenges sentinel status of kelp forests as indicators of climate change. Nat Commun. https://doi.org/10.1038/ ncomms 13757 
Rogers-Bennett L, Catton CA (2019) Marine heat wave and multiple stressors tip bull kelp forest to sea urchin barrens. Sci Rep-Uk. https://doi.org/10.1038/s41598-019-51114-y

Rogers-Bennett L, Dondanville RF, Moore JD, Vilchis LI (2010) Response of red abalone reproduction to warm water, starvation, and disease stressors: Implications of ocean warming. J Shellfish Res 29:599-611. https://doi.org/10.2983/035.029.0308

Rupp JH (1973) Effects of temperature on fertilization and early cleavage of some tropical echinoderms, with emphasis on EchinometraMathaei. Mar Biol 23:183-189. https://doi.org/10.1007/Bf003 89483

Sanford E, Sones JL, Garcia-Reyes M, Goddard JHR, Largier JL (2019) Widespread shifts in the coastal biota of northern California during the 2014-2016 marine heatwaves. Sci Rep-Uk. https://doi.org/ 10.1038/s41598-019-40784-3

Seebacher F, Beaman J, Little AG (2014) Regulation of thermal acclimation varies between generations of the short-lived mosquitofish that developed in different environmental conditions. Funct Ecol 28:137-148. https://doi.org/10.1111/1365-2435.12156

Sen Gupta A, Thomsen M, Benthuysen JA, Hobday AJ, Oliver ECJ, Alexander LV, Burrows MT, Donat MG, Feng M, Holbrook NJ, Perkins-Kirkpatrick SE, Moore PJ, Rodrigues RR, Scannell HA, Taschetto AS, Ummenhofer CC, Wernberg T, Smale DA (2020) Drivers and impacts of the most extreme marine heatwaves events. Sci Rep-Uk. https://doi.org/10.1038/s41598-020-75445-3

Seuront L, Nicastro KR, Zardi GI, Goberville E (2019) Decreased thermal tolerance under recurrent heat stress conditions explains summer mass mortality of the blue mussel Mytilus edulis. Sci Rep-Uk. https://doi.org/10.1038/s41598-019-53580-w

Sewell MA, Young CM (1999) Temperature limits to fertilization and early development in the tropical sea urchin Echinometra lucunter. J Exp Mar Biol Ecol 236:291-305. https://doi.org/10.1016/S00220981(98)00210-X

Sewell MA, Millar RB, Yu PC, Kapsenberg L, Hofmann GE (2014) Ocean acidification and fertilization in the antarctic sea urchin Sterechinus neumayeri: The importance of polyspermy. Environ Sci Technol 48:713-722. https://doi.org/10.1021/es402815s

Shanks AL, Rasmuson LK, Valley JR, Jarvis MA, Salant C, Sutherland DA, Lamont EI, Hainey MAH, Emlet RB (2020) Marine heat waves, climate change, and failed spawning by coastal invertebrates. Limnol Oceanogr 65:627-636. https://doi.org/10.1002/ lno. 11331

Smale DA, Wernberg T, Oliver ECJ, Thomsen M, Harvey BP, Straub SC, Burrows MT, Alexander LV, Benthuysen JA, Donat MG, Feng M, Hobday AJ, Holbrook NJ, Perkins-Kirkpatrick SE, Scannell HA, Sen Gupta A, Payne BL, Moore PJ (2019) Marine heatwaves threaten global biodiversity and the provision of ecosystem services. Nat Clim Change. https://doi.org/10.1038/ s41558-019-0412-1
Steer MA, Moltschaniwskyj MA, Nichols DS, Miller M (2004) The role of temperature and maternal ration in embryo survival: using the dumpling squid Euprymna tasmanica as a model. J Exp Mar Biol Ecol 307:73-89. https://doi.org/10.1016/j.jembe.2004.01.017

Stillman JH (2003) Acclimation capacity underlies susceptibility to climate change. Science 301:65-65. https://doi.org/10.1126/scien ce. 1083073

Strathmann MF (1987) Reproduction and development of marine invertebrates of the Northern Pacific Coast. University of Washington Press

Suckling CC, Clark MS, Richard J, Morley SA, Thorne MAS, Harper EM, Peck LS (2015) Adult acclimation to combined temperature and $\mathrm{pH}$ stressors significantly enhances reproductive outcomes compared to short-term exposures. J Anim Ecol 84:773-784. https://doi.org/10.1111/1365-2656.12316

Thurman LL, Stein BA, Beever EA, Foden W, Geange SR, Green N, Gross JE, Lawrence DJ, LeDee O, Olden JD, Thompson LM, Young BE (2020) Persist in place or shift in space? Evaluating the adaptive capacity of species to climate change. Front Ecol Environ. https://doi.org/10.1002/fee.2253

Uthicke S, Liddy M, Nguyen HD, Byrne M (2014) Interactive effects of near-future temperature increase and ocean acidification on physiology and gonad development in adult Pacific sea urchin. Echinometra Sp a Coral Reefs 33:831-845. https://doi.org/10. 1007/s00338-014-1165-y

Wernberg T, Bennett S, Babcock RC, de Bettignies T, Cure K, Depczynski M, Dufois F, Fromont J, Fulton CJ, Hovey RK, Harvey ES, Holmes TH, Kendrick GA, Radford B, Santana-Garcon J, Saunders BJ, Smale DA, Thomsen MS, Tuckett CA, Tuya F, Vanderklift MA, Wilson S (2016) Climate-driven regime shift of a temperate marine ecosystem. Science 353:169-172. https://doi. org/10.1126/science.aad8745

Yamada K, Mihashi K (1998) Temperature-independent period immediately after fertilization in sea urchin eggs. Biol Bull 195:107111. https://doi.org/10.2307/1542817

Yorke CE, Page HM, Miller RJ (2019) Sea urchins mediate the availability of kelp detritus to benthic consumers. P Roy Soc B-Biol Sci. https://doi.org/10.1098/rspb.2019.0846

Zippay ML, Helmuth B (2012) Effects of temperature change on mussel, Mytilus. Integr Zool 7:312-327. https://doi.org/10.1111/j. 1749-4877.2012.00310.x

Publisher's Note Springer Nature remains neutral with regard to jurisdictional claims in published maps and institutional affiliations. 